\title{
Ecosystem approaches to mercury and human health: A way toward the future
}

\author{
This article belongs to Ambio's 50th Anniversary Collection. Theme: Environmental \\ contaminants
}

Donna Mergler

Published online: 19 January 2021

Ambio is well-known for its interdisciplinary approach to environmental issues and interest in cross-disciplinary research that advances both scientific knowledge and policy-making. For the organizers of the 8th Conference on Mercury as a Global Pollutant, held in 2006, Ambio was the ideal journal to present the principal findings and consensus conclusions of four expert panels, who examined key policy-relevant questions concerning atmospheric sources of mercury, methylmercury exposure and its effects on humans and wildlife, socioeconomic consequences of mercury pollution, and recovery of mercury-contaminated fisheries. The Madison Declaration on Mercury Pollution, published in volume 36 (2007), included consensus statements from the panels. As first author of the article, written by the panel on health risks and toxic effects of methylmercury, entitled: Methylmercury Exposure and Health Effects in Humans: A Worldwide Concern (Mergler et al. 2007), I examine, here, our work with respect to Ambio's mission.

The importance of Ambio's appeal to a wide range of disciplines and its contribution to cross-disciplinary research and policy is well-illustrated in the following statistical comparison. According to the Web of Science, which covers a very wide range of scientific journals, this article on the health effects of mercury in humans has been cited 736 times, ${ }^{1}$ almost five times more than the number of citations $(n=154)$ recorded, at the same date, in Pubmed $^{2}$, which is limited to articles in the biomedical literature. Ambio indeed provided this work on mercury exposure and human health, a platform to provide input to a wide number of disciplines and approaches.

\section{EXPOSURE TO METHYLMERCURY}

Methylmercury is a highly toxic compound that biomagnifies through the aquatic food web, placing at risk humans who consume significant quantities of predatory fish from upper trophic levels or who rely heavily on fish as a food source. Elevated methylmercury exposure in humans is not restricted to isolated populations, because of worldwide export and availability of commercially caught fish. Rather, human exposure to methylmercury at levels exceeding those considered clearly safe and without risk of adverse effect has been observed across geographic, social, economic, and cultural boundaries.

When the article in Ambio was published, fish consumption and fish-eating birds and mammals were the main known source for $\mathrm{MeHg}$ exposure; the authors mention that there were a few reports about rice Oryza sativa. Since then, a number of studies from Asian countries have identified rice as an important vehicle for exposure. Rothenberg et al. (2014) reviewed 51 studies reporting rice total mercury $(\mathrm{Hg})$ and/or $\mathrm{MeHg}$ concentrations, based on rice cultivated or purchased in 15 countries. Although concentrations were significantly higher in polluted sites compared to non-polluted sites, the percentage of $\mathrm{MeHg}$ did not differ statistically, suggesting comparable mercury methylation rates in paddy soil across these sites and/or similar accumulation of mercury species. A review by Zhao et al. (2020), describes $\mathrm{Hg}$ cycling in the rice paddy ecosystem and an article in Ambio by Hsu-Kim et al. (2018) discusses the need to balance management

\footnotetext{
$\overline{1 \mathrm{Web} \text { of }}$ Science, https://clarivate.com/webofsciencegroup/ solutions/web-of-science/ accessed July 31, 2020.

${ }^{2}$ Pubmed, https://pubmed.ncbi.nlm.nih.gov/. accessed July 31, 2020.
} 
strategies to reduce $\mathrm{MeHg}$ in rice with the need to maximize crop production.

\section{TRENDS IN METHYLMERCURY EXPOSURE AND HUMAN HEALTH}

Present exposures throughout the world are lower than those that produced the historic epidemics of methylmercury poisoning in Japan and Iraq. In many populations, however, there is growing evidence that current exposures are sufficient to alter normal function of several physiological and developmental systems, indicating that methylmercury exposure still constitutes an important public health problem. Long-lasting effects of fetal methylmercury exposure have been described in children throughout the world.

Since that time, an impressive body of research has confirmed these findings, even at very low $\mathrm{Hg}$ concentrations (Karagas et al. 2012; Ha et al. 2017). Today, there are many longitudinal birth cohort studies, which focus on or include $\mathrm{Hg}$, as one of the multiple contaminants to which populations across the world are exposed. Since the 2007 publication, high $\mathrm{Hg}$ exposures among coastal and inland northern Indigenous communities have come to the fore; the former from consumption of marine fish and/or fisheating mammals, the latter from freshwater fish. For many Indigenous communities, this adds to the stress due to climate change (Dudley et al. 2015). A recent article published in Ambio (Callaghan et al. 2020), discusses the importance of improving the dialog between Indigenous communities, researchers, local and decision-makers to address climate change. The need for this type of collaboration is likewise true for $\mathrm{Hg}$ exposure since the vehicle for exposure is often subsistence foods that can likewise contain important concentrations of beneficial nutrients. The Nasivvik Research Chair in Ecosystem Approaches to Northern Health ${ }^{3}$ provides a good example of a multisectorial approach to these complex issues.

\section{BIOMARKERS OF METHYLMERCURY EXPOSURE IN HUMANS}

Concentrations of mercury in hair and blood (including umbilical cord blood) are both valid biomarkers of methylmercury exposure. Each measure conveys somewhat different information on exposure, and the most useful picture of exposure is obtained by data from both

$\overline{3}$ http://en.nasivvik.chaire.ulaval.ca/. accessed July 31, 2020. biomarkers, along with dietary information on the fish species consumed and other dietary data. Total fish consumption-without differentiating the fish species consumed-is not necessarily a dependable metric for estimating methylmercury exposure.

Indeed, $\mathrm{Hg}$ concentrations in umbilical cord blood, blood and hair are extensively used as exposure biomarkers in populational studies; some studies have used breastmilk, meconium, fingernail and/or toenail $\mathrm{Hg}$. In general, hair is 250 to 300 times more concentrated in mercury than is blood. This ratio is in common use in research, governmental documents and the World Health Organization (Legrand et al. 2010). However, a review of $\mathrm{Hg}$ research, carried out by a plenary panel at the 12th International Conference on Mercury as a Global Pollutant (Ha et al. 2017), held in 2016, question the use of this metric, citing studies that show large variations in hair-to-blood ratio. Indeed, each biomarker reflects different time periods of exposure and the kinetics with respect to $\mathrm{Hg}$ intake are different. Unfortunately, despite a growing interest, little is still known about the factors that may modulate $\mathrm{Hg}$ absorption in humans, and research is needed to better understand this complex issue.

The amount of MeHg taken up in animals or plants depends upon the degree of pollution of their external environment and for fish, its feeding habits and size. Today, in many countries, consumption guidelines for $\mathrm{MeHg}$ exposure include fish species, and fishing guidelines refer, as well, to the size of the fish. For fish consumption, there is growing recognition that not only is the external ecosystem important to the understanding of the health effects of $\mathrm{MeHg}$ exposure, but so is the "internal ecosystem" or co-occurrence of beneficial nutrients. Omega-3 fatty acids and/or selenium, have been shown to counteract some of the harmful effects of MeHg (Fillion et al. 2013; Jacobson et al. 2015). To maximize nutritional benefit and minimize toxic risk, some guidelines for fish consumption include both $\mathrm{Hg}$ and fatty acid concentrations for different fish species.

\section{RISK ASSESSMENT}

Methylmercury is a developmental neurotoxin, and its developmental neurotoxicity to the fetus constitutes the current basis for risk assessments and public health policies. Uncertainties remain in the risk assessment for the neurodevelopmental effects of methylmercury. Yet there is sufficient evidence to warrant the prudent selection of fish species in the diet, particularly for pregnant women and children.

Engleson and Herner (1952) from the University Hospital Lund, Sweden described the first cases of severe 
organic $\mathrm{Hg}$ poisoning in two infants from the same family. The mother was asymptomatic, and both children appeared normal at birth. The authors surmised that $\mathrm{Hg}$ intoxication, perhaps during early fetal life, may be a possible cause. In 1958, Professor Kitamura discovered that many infants from Minamata, born after 1955, displayed symptoms resembling cerebral palsy and wrote: "It is possible that the substance causing the poisoning was transferred to the infants through the placenta or mother's milk, producing symptoms similar to those of Minamata disease" (cited in Harada 1978). Subsequent epidemiological and pathological studies identified in 1962, methylmercury poisoning via the placenta (Harada 1978). Since that time, we have learned that not only does methylmercury cross the placenta, but it is actively transported; cord blood $\mathrm{Hg}$ concentration is, approximately, 1.7 times that of maternal blood (Mergler et al. 2007).

Because the developing fetal brain is so highly sensitive to $\mathrm{Hg}$ poisoning, it is considered the most adequate endpoint for risk assessment by governmental and international agencies. Today, throughout the globe, birth cohort studies are examining the relation between prenatal mercury exposure and childhood neurodevelopment; most report dose-related neurocognitive deficits, even at low concentrations. (Ha et al. 2017). While most studies have focused on fish-eating populations, a recent study from China showed intellectual deficits in children exposed to methylmercury through contaminated rice (Feng et al. 2020). Loss of intellectual abilities has important social and economic consequences (Trasande et al. 2006, 2016).

In 2007, the panel noted that uncertainties remain in the risk assessment for the neurodevelopmental effects of methylmercury and that is still true today. Despite a large number of studies on the possible role of genetics, many essential nutrients, gut microbiota and the co-occurrence of other contaminants, there are still uncertainties probably due to the wide variety of external ecosystems in which methylmercury is incorporated into the animals and/or plants and the human situations in which methylmercury exposure and effects occur.

A recently published analysis of $\mathrm{Hg}$ concentrations in blood and urine samples of pregnant women and children, collected between 1999 and 2016 as part of the United States National Health and Nutrition Examination Survey, showed an increase in organic $\mathrm{Hg}$ and a decrease in inorganic $\mathrm{Hg}$ (So et al. 2020); the increase in organic $\mathrm{Hg}$ parallels the reported increase in seafood consumption. These finding stress that importance of continuing to examine and update risk assessment within a more global dietary contest.

\section{METHYLMERCURY AND OMEGA-3 FATTY ACIDS}

Fish can contain both methylmercury and beneficial omega3 fatty acids. Methylmercury exerts toxicity and can also diminish the beneficial health effects of omega-3 fatty acids. As with mercury, there are large variations in the level of omega-3 fatty acids in fish. Selection of fish species for consumption should maximize the intake of beneficial fatty acids, whereas limiting the exposure to methylmercury.

The large majority of epidemiologic studies on health effects of $\mathrm{Hg}$, including those used to establish reference values, were carried out on marine fish consumers. The findings have been applied to all fish-eaters, including those whose diet contain primarily or solely freshwater fish. Freshwater fish, which likewise vehicle methylmercury, have lower concentrations of omega- 3 fatty acids, the ratio of total n-3 to n- 6 fatty acids is much higher compared to freshwater fish than for marine fish (Seabert et al. 2014).

There is a very extensive literature on the beneficial effects of omega-3 fatty acids from seafood consumption, but few studies have examined the effects freshwater fish consumers. According to international sources, freshwater capture fisheries account for only $7 \%$ of reported global fish harvests, concentrated in low-income countries and in Indigenous communities in some industrialized countries.

Since 1976, Ambio has published many articles concerning freshwater fish, several of which addressed $\mathrm{Hg}$ contamination in different areas of the globe: Thailand, the Amazon, the Arctic and Sweden. In a study of $\mathrm{Hg}$ and omega-3 fatty acids in the Canadian Northwest Territories (Laird et al. 2018), negative associations were observed between $\mathrm{Hg}$ and N-3 PUFAs in several freshwater fish, and like $\mathrm{Hg}$, differences were observed in fatty acid and $\mathrm{Hg}$ profiles across lakes, underscoring the importance of considering both species- and lake-specific findings for risks and benefits.

\section{CARDIOVASCULAR EFFECTS OF METHYLMERCURY}

Current studies suggest that exposure to methylmercury could increase the risk of adverse cardiovascular effects in a significant fraction of the human population. Reported effects include cardiovascular disease (coronary heart disease, myocardial infarction, ischemic heart disease), increased blood pressure and hypertension, and altered heart rate. The strongest cause-effect evidence is for cardiovascular disease, particularly myocardial infarction in adult men. 
When the panel wrote the article in 2007, there was some evidence of a link between methylmercury exposure and cardiovascular disorders, but the findings were inconsistent (for review see: Chan and Egeland 2004; Stern 2005). As research continued, in 2011, the U.S. Environmental Protection Agency convened a workshop to review the evidence with a view to possible regulation; the participants concluded that a dose-response function relating methylmercury and myocardial infarction and should be established for regulatory purposes. (Roman et al. 2011). More recently, Hu et al. (2018), published a systemic review and meta-analysis of 29 studies that examined blood pressure and hypertension in relation to biomarkers of mercury exposure; the authors observed no or weak associations from studies of populations with low-to-moderate mercury exposure and positive association among populations with high mercury exposures. Again, beneficial nutriments, present in marine fish and seafood, may counteract, to differing extents, the harmful effects of mercury exposure.

\section{CONCLUSIONS}

On this 50th anniversary, we salute Ambio's role in promoting cross-disciplinary research, relevant for decision and policy-making. The health effects of mercury, like other environmental pollutants, need to be considered in the context of an ecosystem approach to health, as described by Webb et al. (2010), which seek to shift the research paradigm to one that embraces transdisciplinarity, social justice, gender equity, multi-stakeholder participation and sustainability. In this context, interventions can be based on understanding the why's and where's of this pollutant, how it circulates in the global environment and the local ecosystems, how it affects people's health, and how, in turn poor health affects social and economic development.

\section{REFERENCES}

Callaghan, T.V., O. Kulikova, L. Rakhmanova, E. Topp-Jørgensen, N. Labba, L.A. Kuhmanen, S. Kirpotin, O. Shaduyko, et al. 2020. Improving dialogue among researchers, local and Indigenous peoples and decision-makers to address issues of climate change in the North. Ambio 49: 1161-1178. https://doi.org/10. 1007/s13280-019-01277-9.

Chan, H.M., and G.M. Egeland. 2004. Fish consumption, mercury exposure, and heart diseases. Nutrition Reviews 62: 68-72.

Dudley, J.P., E.P. Hoberg, E.J. Jenkins, and A.J. Parkinson. 2015. Climate change in the North American Arctic: A one health perspective. EcoHealth 12: 713-725.

Engleson, G., and T. Herner. 1952. Alkyl mercury poisoning. Acta Paediatrica 41: 289-294.
Feng, L., C. Zhang, H. Liu, P. Li, X. Hu, H. Wang, H.M. Chan, and X. Feng. 2020. Impact of low-level mercury exposure on intelligence quotient in children via rice consumption. Ecotoxicology and Environmental Safety 202: 110870.

Fillion, M., M. Lemire, A. Philibert, B. Frenette, H.A. Weiler, J.R. Deguire, J.R. Guimarães, F. Larribe, et al. 2013. Toxic risks and nutritional benefits of traditional diet on near visual contrast sensitivity and color vision in the Brazilian Amazon. Neurotoxicology 37: 173-181.

Ha, E., N. Basu, S. Bose-O'Reilly, J.G. Dórea, E. McSorley, M. Sakamoto, and H.M. Chan. 2017. Current progress on understanding the impact of mercury on human health. Environmental Research 152: 419-433.

Harada, M. 1978. Congenital minamata disease: Intrauterine methylmercury poisoning. Teratology 18: 285-288.

Hsu-Kim, H., C.S. Eckley, D. Achá, X. Feng, C.C. Gilmour, S. Jonsson, and C.P.J. Mitchell. 2018. Challenges and opportunities for managing aquatic mercury pollution in altered landscapes. Ambio 47: 141-169. https://doi.org/10.1007/s13280-017-1006-7.

Hu, X.F., K. Singh, and H.M. Chan. 2018. Mercury exposure, blood pressure, and hypertension: A systematic review and doseresponse meta-analysis. Environmental Health Perspectives 126: 076002.

Jacobson, J.L., G. Muckle, P. Ayotte, É. Dewailly, and S.W. Jacobson. 2015. Relation of prenatal methylmercury exposure from environmental sources to childhood IQ. Environmental Health Perspectives 123: 827-833.

Karagas, M.R., A.L. Choi, E. Oken, M. Horvat, R. Schoeny, E. Kamai, W. Cowell, P. Grandjean, et al. 2012. Evidence on the human health effects of low-level methylmercury exposure. Environmental Health Perspectives 120: 799-806.

Laird, M.J., J.J.A. Henao, E.S. Reyes, K.D. Stark, G. Low, H.K. Swanson, and B.D. Laird. 2018. Mercury and omega-3 fatty acid profiles in freshwater fish of the Dehcho Region, Northwest Territories: Informing risk benefit assessments. Science of the Total Environment 637-638: 1508-1517.

Legrand, M., M. Feeley, C. Tikhonov, D. Schoen, and A. Li-Muller. 2010. Methylmercury blood guidance values for Canada. Canadian Journal of Public Health 101: 28-31.

Lindberg, S., R. Bullock, R. Ebinghaus, D. Engstrom, X. Feng, W. Fitzgerald, N. Pirrone, E. Prestbo, et al. 2007. The madison declaration on mercury pollution. Ambio 36: 62-65. https://doi. org/10.1579/0044-7447(2007)36\%5b62:TMDOMP\%5d2.0. $\mathrm{CO} ; 2$.

Mergler, D., H.A. Anderson, L.H.M. Chan, K.R. Mahaffey, M. Murray, M. Sakamoto, and A.H. Stern. 2007. Panel on health risks and toxicological effects of methylmercury. Methylmercury exposure and health effects in humans: A worldwide concern. Ambio 36: 3-11. https://doi.org/10.1579/00447447(2007)36[3:meahei]2.0.co;2

Roman, H.A., T.L. Walsh, B.A. Coull, É. Dewailly, E. Guallar, D. Hattis, K. Mariën, J. Schwartz, A.H. Stern, et al. 2011. Evaluation of the cardiovascular effects of methylmercury exposures: Current evidence supports development of a doseresponse function for regulatory benefits analysis. Environmental Health Perspectives 119: 607-614.

Rothenberg, S.E., L. Windham-Myers, and J.E. Creswell. 2014. Rice methylmercury exposure and mitigation: A comprehensive review. Environmental Research 133: 407-423.

Seabert, T.A., S. Pal, B.M. Pinet, F. Haman, M.A. Robidoux, P. Imbeault, E.M. Krümmel, L.E. Kimpe, et al. 2014. Elevated contaminants contrasted with potential benefits of $\mathrm{v}-3$ fatty acids in wild food consumers of two remote first nations communities in Northern Ontario, Canada. PLoS ONE 9: e90351.

So, S.C.A., M.F. Tsoi, A.J. Cheung, T.T. Cheung, and B.M.Y. Cheung. 2020. Blood and Urine inorganic and organic mercury 
levels in the United States from 1999 to 2016. The American Journal of Medicine 18.

Stern, A.H. 2005. A review of the studies of the cardiovascular health effects of methylmercury with consideration of their suitability for risk assessment. Environmental Research 98: 133-142.

Trasande, L., J. DiGangi, D.C. Evers, J. Petrlik, D.G. Buck, J. Šamánek, B. Beeler, M.A. Turnquist, et al. 2016. Economic implications of mercury exposure in the context of the global mercury treaty: Hair mercury levels and estimated lost economic productivity in selected developing countries. Journal of Environmental Management 183: 229-235.

Trasande, L., C. Schechter, K.A. Haynes, and P.J. Landrigan. 2006. Applying cost analyses to drive policy that protects children: Mercury as a case study. Annals of the New York Academy of Sciences 1076: 911-923.
Webb, J.C., D. Mergler, M.W. Parkes, J. Saint-Charles, J. Spiegel, D. Waltner-Toews, A. Yassi, and R.F. Woollard. 2010. Tools for thoughtful action: The role of ecosystem approaches to health in enhancing public health. Canadian Journal of Public Health 101: 439-441.

Zhao, L., B. Meng, and X. Feng. 2020. Mercury methylation in rice paddy and accumulation in rice plant: A review. Ecotoxicology and Environmental Safety 195: 110462.

Publisher's Note Springer Nature remains neutral with regard to jurisdictional claims in published maps and institutional affiliations.

Donna Mergler $(\bowtie)$

Address: Université du Québec à Montréal, Montréal, Canada. e-mail: mergler.donna@uqam.ca 